\title{
LA INTERVENCIÓN ADMINISTRATIVA EN LA PLANIFICACIÓN URBANA COMO RESPUESTA A LA PROBLEMÁTICA SOCIAL DERIVADA DE LOS PROCESOS DE GENTRIFICACIÓN TURÍSTICA EN LAS CIUDADES
}

Government intervention in urban planning as a response to the social problem derived from the tourism gentrification processes in the cities

\section{DOI: http://dx.doi.org/10.15304/dereito.29.Ext.6628}

MontserRat María Otero Oitavén

Profesora asociada de Derecho Administrativo

Universidad de Vigo

ORCID ID: https://orcid.org/0000-0001-5918-1035

mootero@uvigo.es

\section{RESUMEN}

El auge de las viviendas de uso turístico, especialmente a través de plataformas tecnológicas está ocasionando, en ocasiones, efectos negativos sobre la población local.

Como respuesta a este proceso, algunos municipios están ejerciendo sus competencias en planificación urbanística con el fin de evitar la concentración excesiva de alojamientos turísticos en determinadas zonas y proceder a una distribución eficiente conforme a lo deseable para la sociedad. Para ello, se utilizan técnicas de intervención propias del derecho administrativo, como la zonificación urbanística y el derecho sancionador bajo la justificación de armonizar los sectores económicos con la protección del medio ambiente y el territorio, ambos valores superiores de alcance constitucional.

Analizaremos las medidas de intervención administrativa en la planificación urbana, especialmente la utilización de la técnica de zonificación, como posibles soluciones a la problemática derivada de los procesos de gentrificación turística en las ciudades.

Palabras clave: viviendas de uso turístico, intervención administrativa, planificación urbana, zonificación, gentrificación

\section{ABSTRACT}

The boom in housing for tourist use, especially through technological platforms, is sometimes causing negative effects on the local population.

In response to this process, some city council are exercising their powers in urban planning in order to avoid the excessive concentration of tourist accommodation in certain areas and proceed to an efficient distribution according to what is desirable for society. For this, intervention techniques typical of administrative law are used, such as urban zoning and sanctioning law under the justification of harmonizing the economic sectors with the protection of the environment and the territory, both higher values of constitutional scope.

We will analyze administrative intervention measures in urban planning, especially the use of the zoning technique, as possible solutions to the problems derived from the processes of tourist gentrification in cities. 
Keywords: Tourist accommodation, government intervention, urban planning, zoning, gentrification

\section{SUMARIO}

1. ANTECEDENTES. 1.1. La importancia del sector turístico en España. 1.2. El auge de las viviendas de uso turístico. Externalidades positivas y negativas. 1.3. Las viviendas de uso turístico y su impacto social: la gentrificación y la turistificación. Consecuencias de la rentabilidad de las viviendas sobre la actividad económica. 2. LA INTERVENCIÓN ADMINISTRATIVA. 2.1. La aplicación de la Directiva de Servicios. 2.2. La justificación de la planificación urbanística como técnica de intervención administrativa en el mercado de las viviendas de uso turístico. 2.3. La técnica de zonificación como límite al establecimiento de viviendas de uso turístico. 3. REFLEXIONES FINALES. 4. BIBLIOGRAFÍA

\section{ANTECEDENTES}

\subsection{LA IMPORTANCIA DEL SECTOR TURÍSTICO EN ESPAÑA}

España es una de las potencias turísticas más importantes a nivel mundial. En el año 2018 fue la quinta mayor economía turística de la Unión Europea (por detrás de Alemania, Reino Unido, Italia y Francia) en términos de contribución al PIB. El sector turístico contribuye con 178.000 millones de euros a la economía española, representa el $14,6 \%$ del PIB nacional y da empleo a 2,8 millones de trabajadores en España, lo que supone un 14,7\% del empleo total. Las previsiones apuntan a que, en el año 2029, el número de trabajadores del sector turístico en nuestro país se incrementará hasta los 3,8 millones ${ }^{1}$.

\subsection{EL AUGE DE LAS VIVIENDAS DE USO TURÍSTICO. EXTERNALIDA- DES POSITIVAS Y NEGATIVAS}

Los modelos de negocio de las viviendas de uso turístico (VUT) han sufrido una fuerte transformación en los últimos años, especialmente como consecuencia del desarrollo tecnológico que ha permitido la creación de plataformas colaborativas. Estas plataformas se caracterizan por ser mercados de varios lados que operan sobre segmentos independientes de prosumidores (productor y consumidor a la vez) que se benefician mutuamente de un efecto de red, de manera que para que uno de los lados del mercado reciba valor, debe existir el otro. Estas plataformas constituyen nuevos sistemas de producción y consumo de bienes y servicios que han surgido gracias a las posibilidades que ofrecen las tecnologías de la información para facilitar los intercambios de bienes y servicios y son fundamentales en el desarrollo de la economía colaborativa.

Según un estudio publicado por la CNMC, la inversión en el periodo 2000 -2015, a nivel mundial, en plataformas de economía colaborativa relacionadas con el alojamiento turístico supone el $18 \%$ del total, lo que significa que este sector es uno de los que atrae mayor inversión, tras el transporte².

\footnotetext{
${ }^{1}$ Datos de World Travel \& Tourism Council. Disponible on line en https://www.wttc.org/economic-impact/ (último acceso: 20 de julio de 2019).

${ }^{2}$ Comisión Nacional de los Mercados y la Competencia (CNMC), Resultados preliminares del estudio de los nuevos modelos de prestación de servicios y la economía colaborativa, 2016. Disponible en https://docs.google.com/document/d/1n65MjUaTmRLuZCqTIlayWvobVqreRiAzsz1mhxy2y0/edit?pref=2\&pli=1\# (Último acceso: 20 de julio de 2019).
} 
Una de las consecuencias de este incremento del volumen de transacciones en las plataformas digitales en el sector del alojamiento es la relacionada con la expansión territorial de las viviendas turísticas. Hasta hace unos años, el turismo se encontraba acotado a determinadas zonas, normalmente en los centros de las ciudades y urbanísticamente delimitado por estar vinculado a determinadas tipologías edificatorias del sector terciario (hoteles y apartamentos, principalmente). En la actualidad, la oferta y la demanda turística han rebasado esos márgenes, permitiendo que penetren en el tejido de las ciudades y confundiéndose con las tipologías habitacionales propias del espacio urbano (residencia unifamiliar y plurifamiliar) ${ }^{3}$.

Debido a las diferentes consecuencias que este nuevo paradigma del sector turístico tiene sobre la sociedad y sobre los mercados, el incremento de las VUT propiciado por las plataformas colaborativas cuenta con partidarios y detractores.

Entre las externalidades positivas que se suelen señalar figuran las siguientes:

- Aumento del número de plazas turísticas en las ciudades, sin tener que acometer nuevas construcciones edificatorias.

- Creación de nuevas experiencias para el turista, que puede integrarse en la forma de vida del lugar que visita.

- Reducción de los problemas de información asimétrica gracias a los sistemas de reputación online, permitiendo, por una parte, que el turista obtenga una mayor información acerca de las características y servicios de la vivienda y, por otra parte, facilitando que el anfitrión conozca el comportamiento de los usuarios y pueda rechazarlos como huéspedes en su vivienda. - Rentabilización de viviendas infrautilizadas y asignación eficiente de recursos, posibilitando que los propietarios de las viviendas obtengan unos ingresos extra que pueden contribuir a cubrir los costes derivados de la adquisición o mantenimiento de estas.

- Distribución de la presión turística, permitiendo que la oferta de viviendas se expanda por todo el territorio de la ciudad y no solo en la zona centro, lo cual, supone además un beneficio para el comercio local de esas zonas.

Sin embargo, no todo son ventajas. Entre las externalidades negativas que podrían llegar a producirse podemos señalar las siguientes:

- Intrusismo y competencia desleal.

- Problemas de convivencia entre ciudadanos y turistas derivados del ruido, trasiego, limpieza y vandalismo, en algunos casos.

- Encarecimiento de los precios de adquisición y de arrendamiento de viviendas de larga duración, así como transformación social en el centro de las ciudades, provocando procesos de gentrificación urbana.

- Fraude fiscal.

Sin duda, durante los últimos años y, especialmente, a raíz de la crisis financiera mundial, el alquiler de las VUT ha supuesto una importante vía de

\footnotetext{
${ }^{3}$ En este sentido, J.M. SOCÍAS CAMACHO, "Estado regulador y alojamiento «colaborativo» en VV.AA. (A. M. de la Encarnación, dir.) La regulación del alojamiento colaborativo. Viviendas de uso turístico y alquiler de corta estancia en el Derecho español, Thomson Reuters Aranzadi, Navarra, 2018, pp. 95-119.
} 
obtención de ingresos para los propietarios de viviendas que no constituían su primera residencia y que no estaban dispuestos a optar por un arrendamiento tradicional de larga duración, así como para los propietarios de viviendas que vieron cómo su residencia habitual también podía generar unos ingresos adicionales para su economía.

\subsection{LAS VIVIENDAS DE USO TURÍSTICO Y SU IMPACTO SOCIAL: LA GENTRIFICACIÓN Y LA TURISTIFICACIÓN. CONSECUENCIAS DE LA RENTABILIDAD DE LAS VIVIENDAS SOBRE LA ACTIVIDAD ECONÓMICA}

La gentrificación no es un fenómeno que haya nacido a raíz del auge de las viviendas turísticas. Hace más de cincuenta años ya se estudiaba este proceso como aquel por el que se produce la llegada de sectores de clase media a algunos barrios obreros y se desarrolla rápidamente hasta que todos o la mayoría de los ocupantes originales de la clase trabajadora son desplazados de y se transforma el carácter del barrio 4 .

Pero no solo el desarrollo urbano tiene incidencia en la transformación social de las ciudades. El turismo masivo produce efectos significativos en las urbes, de forma que en ocasiones se desarrolla la turistificación, que puede ser definida como la transformación de un barrio de clase media en un enclave relativamente rico y exclusivo marcado por una proliferación de espacios de entretenimiento destinados al turismo ${ }^{5}$.

En algunas ciudades, el auge de las VUT ha provocado que actualmente se hable de "doble gentrificación", que se produce por un originario desplazamiento poblacional a causa de las acciones de rehabilitación y regeneración urbanas, que logran que el ámbito sea atractivo para el turista y generando, a su vez, una masificación de servicios que no están destinados a la población residente, sino casi completamente al turista ${ }^{6}$.

Esto puede llegar a desarrollarse en espacios urbanos en los que la concentración de VUT es muy alta, lo que actualmente sucede en algunas zonas de centros históricos de determinadas capitales. La demanda adicional creada por los turistas hace que el comercio de ciertos bienes y servicios en el vecindario sea suficientemente rentable y también puede suceder que las empresas locales cambien su gama de productos hacia otros más deseados por los visitantes, debido a su elevado poder de compra. Esto significa, en algunos casos, la pérdida de un comercio local diario de bienes y servicios para la población residente de la zona, que actualmente se ha descrito como gentrificación minorista?.

Las repercusiones sociales del aumento de VUT en las ciudades no son siempre las mismas. El impacto que se produce por el aumento del turismo no es homogéneo en todas las ciudades, si bien, en algunas, son notables los cambios sociales derivados de este hecho. Tanto es así, que la importancia de este fenómeno y su rápida evolución ha propiciado algunas distorsiones en las urbes $y$, en ocasiones, conflictos entre residentes y turistas.

\footnotetext{
${ }^{4}$ R. GLASS, London aspects of change, MacGibbon \& Kee, Londres, 1965.

${ }^{5}$ K. GOTHAM, "Tourism Gentrification: the case of New Orleans 'Vieux Carré (French Quarter)", Urban Studies, vol. 42, no 7, 2005, pp. 1009-1121.

${ }^{6}$ N.A. GUILLÉN NAVARRO, "Viviendas de uso turístico y turismofobia" en VV.AA. (A. M. de la Encarnación, dir.) La regulación del alojamiento colaborativo. Viviendas de uso turístico y alquiler de corta estancia en el Derecho español, Thomson Reuters Aranzadi, Navarra, 2018, pp. 171-186.

7 N. STORS, A. KAGERMEIER "The sharing economy and its role in metropolitan tourism" en VV.AA. (M. Gravari-Barbas, S. Guinand, ed.) Tourism gentrification in contemporary metropolises, Routledge, Nueva York, 2017, pp. 181-205
} 
En ciudades en las que existe una masificación turística, una de las externalidades que pueden producirse debido al incremento de las VUT es el encarecimiento de los precios de adquisición y arrendamiento de viviendas de larga duración y la transformación social en el centro de las ciudades. Aunque no hay una opinión unánime sobre ello, en ocasiones la transformación de un alquiler de vivienda tradicional en un nuevo arrendamiento vacacional ha sido relacionada en algunos casos con estos efectos negativos sobre la población residente local, manifestados en una alteración de los precios del alquiler y el desplazamiento del vecino residente en favor del turista, así como una alteración en el tejido comercial y social.

Algunos autores apuntan a que la turistificación genera una serie de impactos negativos que pueden clasificarse en los siguientes: a) el aumento de los precios en los mercados inmobiliarios locales, provocando un creciente desplazamiento espacial de los residentes; b) el despojo material y simbólico de los residentes; c) la creciente marginación de ciertas presencias, prácticas y consumos a través de políticas de seguritización —-mediante vigilancia y control policial- de la gestión urbana; d) la promoción de nuevas formas de actividades de ocio hedonista y nocturno mercantilizado, que pueden ejercer presión sobre la habitabilidad de la comunidad; e) la desaparición del comercio minorista tradicional, que es sustituido por comercio elitista o "gurmetizado" dirigido al turismo; y, finalmente, f) la contribución a otros fenómenos urbanos, como la gentrificación ${ }^{8}$.

La alta rentabilidad de las viviendas que se obtiene cuando son arrendadas por cortos espacios de tiempo mediante la intermediación de plataformas colaborativas propicia que esta actividad sea cada vez mayor, especialmente en las zonas centro de algunas ciudades, atrayendo a usuarios profesionales, que cada vez tienen más presencia en este tipo de plataformas. De esta forma, lo que en principio nació como el aprovechamiento temporal de un bien infrautilizado ${ }^{9}$, constituyendo una auténtica economía colaborativa, se ha transformado, en un número importante de casos, en una verdadera actividad económica de carácter profesional. OSKAM ${ }^{10}$ advierte de los diferentes intereses que existen detrás de estas actividades y señala que mientras las iniciativas iniciales de las plataformas colaborativas estaban basadas en viajes sociales y giraban en torno a la idea casi altruista de ofrecer a las personas un lugar para quedarse y compartir experiencias, las empresas convirtieron el concepto de "invitar a extraños a su hogar" en un modelo con fines de lucro.

A este respecto, GIL. ${ }^{11}$ clasifica los perfiles de personas que alquilan viviendas o habitaciones en Airbnb en los siguientes perfiles:

\footnotetext{
${ }^{8}$ En este sentido, C. CABRERIZO, J. SEQUERA, P. BACHILLER, "Entre la turistificación y los espacios de resistencia en el centro de Madrid. Algunas claves para (re)pensar la ciudad turística", Ecología Política, 52, 2016, pp. 78-82.

9 Molly Turner, Global Head of Civic Partnerships en Airbnb señalaba en el año 2013 que el modelo de negocio de Airbnb se basaba en personas que no podían pagar sus hogares y necesitaban más dinero, por ello alquilaban sus casas. M. TURNER, "Global head of civic partnerships at Airbnb", A. Boswijk Interviewer, 2013, en J. OSKAM, A.BOSWIJK, "Airbnb: the future of networked hospitality businesses," Journal of Tourism Futures, Vol. 2, 2016, pp. $22-42$.

10 J. OSKAM, A. BOSWIJK, op. cit.

11 J. GIL, "¿Cómo regular el hospedaje entre particulares? Criterios de regulación utilizando el caso de «Airbnb»" en VV.AA. (A. M. de la Encarnación, dir.) La regulación del alojamiento colaborativo. Viviendas de uso turístico y alquiler de corta estancia en el Derecho español, Thomson Reuters Aranzadi, Navarra, 2018, pp. 121-147.
} 
- Anfitriones esporádicos, que realizan la actividad de manera puntual a lo largo del año, en su primera residencia

- Anfitriones permanentes, que realizan la actividad de manera continuada a lo largo del año, pero en su primera residencia

- Anfitriones profesionales, que realizan la actividad de alquiler vacacional de manera profesional y nunca en su residencia

- Anfitriones inversores, que son propietarios de viviendas o invierten en la compra de vivienda para destinarlas exclusivamente a turistas, en muchos casos, contratan a anfitriones profesionales para que gestionen la actividad.

Las dos primeras formas de realización de la actividad responden a los principios básicos de la economía colaborativa. Sin embargo, en el caso de la actividad realizada por anfitriones profesionales e inversores, parece que nos encontramos ante una actividad económica tradicional. El establecimiento de un criterio que permita categorizar estas formas de actividad resulta imprescindible para poder determinar cuándo nos encontramos ante una transacción que debe ser entendida como un tradicional contrato de alquiler de temporada o, por el contrario, cuándo debemos entender que se trata de un alojamiento de uso turístico que debería estar sujeto, por tanto, a la regulación administrativa. A este respecto, existen varios criterios utilizados tradicionalmente que podrían ser aplicables a esta materia: profesionalidad, habitualidad y prestación de servicios turísticos. DESDENTADO DAROCA $^{12}$ considera que el criterio clave debe ser la profesionalidad, que puede medirse mediante varios parámetros como la prestación de servicios turísticos, el periodo de duración de la cesión de la vivienda y la entidad de la actividad realizada, medida a su vez, por la existencia o no de empleados a tiempo completo o el número de viviendas ofertadas.

\section{LA INTERVENCIÓN ADMINISTRATIVA}

\subsection{LA REGULACIÓN DE LAS VIVIENDAS DE USO TURÍSTICO. LA APLICACIÓN DE LA DIRECTIVA DE SERVICIOS}

Como hemos visto, el uso de VUT puede llegar a generar un impacto sobre el espacio y el medioambiente urbano y, a su vez, cuando es consecuencia de una verdadera actividad económica, incide sobre los principios de libertad de empresa, libre competencia y unidad de mercado. Todo ello obliga al legislador a realizar una profunda regulación de la comercialización turística de las viviendas, constituyendo un reto para el Derecho Administrativo, que debe conseguir un equilibrio entre la salvaguarda de la ciudad como espacio sostenible y la libertad de establecimiento de los operadores económicos, con la dificultad añadida de no invadir espacios que competen al Derecho civil.

El punto de partida de esta regulación es la reforma normativa de la Ley 29/1994, de 24 de noviembre, de arrendamientos urbanos (LAU) operada por la Ley $4 / 2013$, de 4 de junio, de medidas de flexibilización y fomento del mercado del alquiler de vivienda, que en su artículo 5.e) excluye, del ámbito de aplicación de la LAU "la cesión temporal de uso de la totalidad de una vivienda amueblada y equipada en condiciones de uso inmediato, co-

\footnotetext{
${ }^{12}$ E. DESDENTADO DAROCA, "Aspectos jurídico-administrativos de las viviendas de uso turístico" en VV.AA. (M. Lucas Durán, dir.) Las viviendas de uso turístico y su regulación jurídica. Un enfoque multidisciplinar, Thomson Reuters Aranzadi, Navarra, 2019, pp. 41 - 93.
} 
mercializada o promocionada en canales de oferta turística y realizada con finalidad lucrativa, cuando esté sometida a un régimen específico, derivado de su normativa sectorial".

Esta previsión ha sido modificada recientemente por el Real Decreto-ley $7 / 2019$, de 1 de marzo, de medidas urgentes en materia de vivienda y alquiler, que introduce el inciso "comercializada o promocionada en canales de oferta turística o por cualquier otro modo de comercialización o promoción (...)".

La calificación del contrato como de arrendamiento de temporada o como alojamiento turístico es una cuestión fundamental, ya que ello determinará la normativa aplicable al mismo. Si se considera que se trata de una cesión temporal y onerosa del uso de una vivienda sin que se incluya ningún otro servicio por parte del arrendador en favor del arrendatario, nos encontraremos ante un contrato de arrendamiento de temporada de los definidos en el artículo 3 LAU y regulado, por tanto, por la misma y, supletoriamente, por el Código Civil. Por el contrario, si el arrendamiento incluye la cesión de un bien acompañado de servicios propiamente turísticos por parte del arrendador, nos encontraremos ante una cesión temporal de uso de vivienda, excluida expresamente del ámbito de aplicación de la LAU y regulada por la normativa sectorial.

En los últimos años las Comunidades Autónomas han regulado el alojamiento turístico con mayor o menor intensidad, generando un debate, en ocasiones tenso y una inquietud social y empresarial acerca de cuáles deben ser los límites y las reglas que rijan esta actividad.

Como señala FRANCH FLUXÁ13

"Son diversos los objetivos y finalidades que deben cumplir las normativas turísticas y para ello las legislaciones autonómicas se han orientado a desarrollar los siguientes aspectos: determinar nuevas obligaciones a los titulares o propietarios en la gestión de su actividad turística, establecer parámetros que permitan mejorar la calidad turística, adoptar medidas para propiciar y garantizar la seguridad ciudadana, fijar requisitos para garantizar la protección de los consumidores, régimen de responsabilidad e implantación de seguros de responsabilidad civil o establecer la obligación a los propietarios o gestores de remitir a la administración información de diverso alcance."

La regulación de las viviendas de uso turístico por parte de las distintas Comunidades Autónomas está derivando en una importante disparidad entre las distintas normativas que puede resultar ineficiente y complejo para el operador económico. El hecho de trasladar a la normativa sectorial turística el fenómeno de la regulación ha dado como resultado una "carencia de uniformidad, por una parte, en cuanto al objeto, y de otra, una ausencia casi total de regulación de las plataformas en sí mismas"14.

La falta de un marco reglamentario común, de carácter estatal, sobre el modelo turístico a seguir y que regule de forma clara algunos aspectos cruciales en esta materia, como pueden ser los estándares mínimos de calidad o la responsabilidad civil de las partes ha provocado una diversidad regula-

\footnotetext{
13 J. FRANCH FLUXÁ, "Las comunidades autónomas ante el alojamiento colaborativo", en VV.AA. (S. Rodríguez Marín y A. Muñoz García, coords.), Aspectos legales de la economía colaborativa y bajo demanda en plataformas digitales, Wolters Kluwer, Madrid, 2018, pp.221-243

${ }_{14}$ M. LORA-TAMAYO VALLVÉ, "Economía colaborativa y alojamiento" en VV.AA. (J.J. Montero Pascual, dir.), La regulación de la economía colaborativa, Tirant lo Blanch, Valencia, 2017
} 
toria en las Comunidades Autónomas, a nuestro juicio, poco recomendable para la planificación y el desarrollo sostenible del sector turístico.

Como sabemos, en concordancia con lo dispuesto en la Directiva 2006/123/CE del Parlamento Europeo y del Consejo, de 12 de diciembre de 2006, relativa a los servicios en el mercado interior (en adelante, Directiva de Servicios), la Ley 17/2009, de 23 de noviembre, sobre el libre acceso a las actividades de servicios y su ejercicio y la Ley 20/2013, de 9 de diciembre, de garantía de la unidad de mercado disponen que una intervención pública que restrinja la competencia solo puede estar amparada en la existencia de un fallo de mercado que ponga en riesgo una o varias razones imperiosas de interés general que el sector público deba proteger. Por ello, las restricciones que las autoridades en materia turística impongan al acceso de la comercialización de las VUT deben guardar la cautela suficiente para no entrar en conflicto con los principios de libertad de empresa, libre competencia, derecho a la propiedad privada y garantía de unidad de mercado.

La Directiva de Servicios establece, en su considerando noveno que

"la presente Directiva solo se aplica a los requisitos que afecten al acceso a una actividad de servicios o a su ejercicio. Así, no se aplica a requisitos tales como normas de tráfico rodado, normas relativas a la ordenación del territorio, urbanismo y ordenación rural, normas de construcción, ni a las sanciones administrativas impuestas por no cumplir dichas normas, que no regulan específicamente o no afectan específicamente a la actividad del servicio pero que tienen que ser respetadas por los prestadores en el ejercicio de su actividad económica al igual que por los particulares en su capacidad privada."

Por tanto, esta Directiva, en principio, no es aplicable a la ordenación del territorio y el urbanismo, pero sí a la regulación de los requisitos de establecimiento de la actividad de las VUT. No obstante, la Directiva de Servicios señala, en el artículo 15.2.a) que en el caso de que se impongan límites cuantitativos o territoriales al acceso a una actividad deberá justificarse que se ajustan a los principios de no discriminación, necesidad y proporcionalidad ${ }^{15}$.

SOCÍAS CAMACHO ${ }^{16}$ considera que se pueden distinguir dos situaciones derivadas de la aplicación de la Directiva de Servicios a la comercialización turística en viviendas. La primera de ellas, relacionada con el ámbito del urbanismo o la ordenación del territorio, en la que cobra una gran importancia la motivación de las medidas territoriales que se adopten y su adecuación a los principios de no discriminación, necesidad y proporcionalidad. La segunda, relacionada con la actividad y las condiciones de prestación del servicio, aspectos sometidos a la Directiva de Servicios y a la legislación de transposición, que regularán el funcionamiento ordinario de la comercialización de las VUT y su régimen de autorizaciones administrativas.

\footnotetext{
15 Véase la sentencia de 30 de enero de 2018 del Tribunal de Justicia de la Unión Europea (ECLI:EU:C:2018:44), en la que se afirma que en virtud de lo dispuesto en el artículo 15.1 de la Directiva de Servicios, los Estados miembros están obligados a examinar si en su ordenamiento jurídico están previstos alguno o algunos de los requisitos establecidos en el apartado 2 del mismo artículo y deben revisar sus disposiciones reglamentarias y administrativas con el fin de asegurar que esos requisitos son acordes con los principios de necesidad, proporcionalidad y no discriminación.

16 J.M. SOCÍAS CAMACHO, "Estado regulador y alojamiento «colaborativo» en VV.AA. (A. M. de la Encarnación, dir.) La regulación del alojamiento colaborativo. Viviendas de uso turístico y alquiler de corta estancia en el Derecho español, Thomson Reuters Aranzadi, Navarra, 2018, pp. 95-119
} 
Sin embargo, la exclusión de la aplicación de la Directiva de Servicios a la planificación urbanística como instrumento para regular los usos de las viviendas no es unánime. Considerando que estas técnicas imponen unos requisitos para el establecimiento de actividades económicas, las autoridades de la competencia se han pronunciado a favor de la aplicación de la Directiva de Servicios en lo que concierne a la planificación urbanística que afecta a las VUT ${ }^{17}$. En opinión de ROMÁN MÁRQUEZ ${ }^{18}$

"Este tipo de planes no responden a la finalidad propia de la planificación urbana, cual es la ordenación arquitectónica de los espacios de la ciudad y las condiciones para su transformación y desarrollo, sino que contiene importantes implicaciones económicas que trascienden a la materia urbanística. La única finalidad de esos planes es regular una determinada actividad económica, por lo que su naturaleza como instrumento urbanístico debe ser puesto en entredicho a los efectos de su exclusión de la Directiva de Servicios, por más que su existencia pueda estar justificada para sus redactores en razones como la supuesta incompatibilidad relativa a los usos del suelo entre la actividad de alojamiento turístico y el uso residencial de las viviendas o en la protección del derecho fundamental a una vivienda digna."

En definitiva, más allá de las diferentes posiciones acerca de la exclusión o no de la materia de la Directiva de Servicios, lo cierto es que, siguiendo a NOGUEIRA LÓPEZ ${ }^{19}$ desde la perspectiva de la intervención administrativa el elemento que se debe tener en consideración para articular medidas de control sobre los alojamientos colaborativos es la determinación de la existencia de intereses púbicos que necesitan protección para apreciar si existen razones específicas de interés púbico que hagan necesario regular estos alojamientos de forma diferenciada a la regulación existente para otros alojamientos.

\subsection{LA JUSTIFICACIÓN DE LA PLANIFICACIÓN URBANÍSTICA COMO TÉCNICA DE INTERVENCIÓN ADMINISTRATIVA EN EL MERCADO DE LAS VIVIENDAS DE USO TURÍSTICO}

La regulación de las VUT está íntimamente ligada a la ordenación del territorio y a la política de vivienda. El auge de este tipo de actividad guarda una estrecha relación con el deterioro del medioambiente urbano y el incremento de las necesidades de nuevas dotaciones de infraestructuras, así como las limitaciones al mercado inmobiliario por parte de los ciudadanos. Es por ello por lo que una ordenación racional del territorio resulta esencial para alcan-

\footnotetext{
17 Véase COMISIÓN NACIONAL DE LOS MERCADOS Y LA COMPETENCIA (CNMC) (2018). "Estudio sobre la regulación de las viviendas de uso turístico en España. E/CNMC/003/18" disponible en https://www.cnmc.es/sites/default/files/2133063 2.pdf (Último acceso: 28 de julio de 2019), AUTORITAT CATALANA DE LA COMPETENCIA (ACCO) (2014). "Recomendaciones sobre la regulación detallada de los usos del suelo desde la óptica de la competencia. ES 8/2014". Disponible en http://acco.gencat.cat/web/.content/80 acco/documents/arxius/actuacions/ES 82014 USOS DEL SOL ESP.pdf (Último acceso: 28 de julio de 2019)

${ }^{18}$ A. ROMÁN MÁRQUEZ, "Planificación urbanística del turismo: la regulación de las viviendas de uso turístico en Madrid y Barcelona", Revista de Estudios de la Administración Local y Autonómica, 10, 2018, pp. 22-39

${ }_{19}$ A. NOGUEIRA LÓPEZ, "Las competencias sobre el alojamiento «colaborativo». Entre el «derecho a la ciudad», la garantía de la vivienda y la dura lex económica" en VV.AA. (A. M. de la Encarnación, dir.) La regulación del alojamiento colaborativo. Viviendas de uso turístico y alquiler de corta estancia en el Derecho español, Thomson Reuters Aranzadi, Navarra, 2018, pp. 231-259
} 
zar un desarrollo urbano sostenible y la tan deseada armonización del derecho a la vivienda con el derecho a la explotación de esta.

La Constitución Española establece el derecho a disfrutar de un medio ambiente adecuado para el desarrollo de la persona (art. 45), así como el derecho de los ciudadanos a disfrutar de una vivienda digna y adecuada, para lo cual, los poderes públicos promoverán las condiciones necesarias y establecerán las normas pertinentes para hacer efectivo este derecho 20 .

Los poderes públicos disponen de diversos instrumentos urbanísticos para lograr la finalidad descrita. El legislador ha establecido en el Real Decreto Legislativo $7 / 2015$, de 30 de octubre, por el que se aprueba el texto refundido de la Ley del Suelo y Rehabilitación Urbana que el fin común de las políticas públicas relativas a la regulación, ordenación, ocupación, transformación y uso del suelo es la utilización de este recurso conforme al interés general y según el principio de desarrollo sostenible (art. 3.1) y para ello, las políticas deben, entre otras cuestiones: propiciar el uso racional de los recursos naturales armonizando los requerimientos de la economía, la cohesión social y la protección del medio ambiente, posibilitando el uso residencial en viviendas constitutivas de domicilio habitual en un contexto urbano seguro, salubre, accesible universalmente, de calidad adecuada e integrado socialmente; favorecer y fomentar la dinamización económica y social y la adaptación, la rehabilitación y la ocupación de las viviendas vacías o en desuso; integrar en el tejido urbano cuantos usos resulten compatibles con la función residencial, para contribuir al equilibrio de las ciudades y de los núcleos residenciales, favoreciendo la diversidad de usos, la aproximación de los servicios, las dotaciones y los equipamientos a la comunidad residente, así como la cohesión y la integración social.

Dispone, además, que "el suelo vinculado a un uso residencial por la ordenación territorial y urbanística está al servicio de la efectividad del derecho a disfrutar de una vivienda digna y adecuada, en los términos que disponga la legislación en la materia" (art. 3.4 in fine).

En consecuencia, los poderes públicos que tengan atribuidas competencias urbanísticas deben garantizar que la utilización de la vivienda es compatible tanto con el uso residencial como con el uso turístico. Siguiendo a SOCÍAS CAMACHO ${ }^{21}$ los poderes públicos

"están plenamente legitimados para regular y limitar -mediante técnica de la zonificación- el alquiler turístico en viviendas en aras a compatibilizar el uso turístico del espacio urbano con el uso residencial, de acuerdo con la función social de la propiedad, la protección del medio ambiente, el principio de desarrollo urbano sostenible, la protección del entorno urbano y los objetivos de política social".

Dentro de los poderes públicos, los Ayuntamientos son la Administración que tiene un mayor conocimiento de la realidad urbana de sus municipios y

\footnotetext{
${ }^{20}$ Sobre el marco constitucional español y el desarrollo sostenible véase M. VAQUER CABALLERÍA, "La consolidación del principio de desarrollo territorial y urbano sostenible en la última década", $R e-$ vista de Derecho Urbanístico y Medio Ambiente, 311, 2017, pp. 499-525.

${ }^{21}$ J.M. SOCÍAS CAMACHO, "Estado regulador y alojamiento «colaborativo» en VV.AA. (A. M. de la Encarnación, dir.) La regulación del alojamiento colaborativo. Viviendas de uso turístico y alquiler de corta estancia en el Derecho español, Thomson Reuters Aranzadi, Navarra, 2018, pp. 95-119
} 
perciben de manera más precisa las necesidades de los ciudadanos ${ }^{22}$. Quizás por este motivo son los municipios con mayor presión turística los que están tomando la iniciativa a través de las técnicas de planificación urbanística.

\subsection{LA TÉCNICA DE ZONIFICACIÓN COMO LÍMITE AL ESTABLECIMIENTO DE VIVIENDAS DE USO TURÍSTICO}

La utilización de técnica de zonificación y de calificación urbanística tiene como finalidad combatir las consecuencias negativas de la saturación de viviendas de uso turístico en determinadas áreas de las ciudades, especialmente, el centro de las urbes. El fin último es impedir que se desarrollen procesos de gentrificación que generen impactos en la sociedad y en el entorno urbano. ROMÁN MÁRQUEZ23. señala que, en el caso de la planificación de las ciudades de Madrid y Barcelona, los objetivos fijados por los redactores de los planes pueden concretarse en el uso equilibrado del suelo, la reducción de externalidades negativas y la promoción del derecho a una vivienda digna.

La zonificación requiere una definición previa de las diferentes tipologías de uso con el fin de que los operadores económicos puedan conocer en qué tipología se encuadra la actividad que pretenden desarrollar. Además, se delimitan distintos tipos de zonas turísticas en el planeamiento municipal distinguiendo, normalmente, entre zonas y ámbitos turísticos, zonas turísticamente saturadas y zonas de protección y en consecuencia se restringe el establecimiento de VUT con mayor o menor intensidad.

La prohibición de los usos turísticos en algunas zonas puede ser absoluta o relativa. En ocasiones, las prohibiciones relativas introducen restricciones cuantitativas de manera que imponen un número máximo de plazas turísticas en alojamientos turísticos y el límite máximo de plazas en VUT.

En ese sentido, la Ley 8/2012, de 19 de julio, del turismo de las Illes Balears, en su artículo 5.3, establece:

"Los planes de intervención en ámbitos turísticos (PIAT) y, si procede, los planes territoriales insulares (PTI) pueden establecer la densidad global máxima de población, delimitar zonas y ámbitos turísticos y de protección, y fijar el tamaño y las características, así como establecer parámetros mínimos o máximos de superficie, volumetría, edificabilidad y equipamientos. También pueden delimitar las zonas turísticas saturadas o maduras, de acuerdo con los criterios establecidos en esta ley. Y asimismo, pueden señalar las excepciones que por la ubicación o las características especiales así lo aconsejen".

En el artículo 75.2 dispone que

"A los efectos de esta Ley, tiene la consideración de zona apta para la comercialización de estancias turísticas en viviendas de uso residencial aquella en que, motivadamente, con las medidas correctoras que se puedan establecer y cumpliendo las previsiones establecidas legalmente o reglamentariamente en materia de vivienda, la administración competente

\footnotetext{
22 En este sentido, M.A. ARIAS MARTÍNEZ, "La integración de los inmigrantes y el acceso a la vivienda: un doble reto para la Administración española", Instituzioni del Federalismo. Revista di studi giuridici e politici, 1, 2019

${ }^{23}$ A. ROMÁN MÁRQUEZ," Planificación urbanística del turismo: la regulación de las viviendas de uso turístico en Madrid y Barcelona", Revista de Estudios de la Administración Local y Autonómica, 10, 2018, pp. 22-39
} 
para llevar a cabo la zonificación considere que esta utilización extraordinaria de las viviendas residenciales resulta compatible con el uso ordinario de vivienda que las caracteriza. Si lo considera conveniente, la administración para llevar a cabo la zonificación puede solicitar informe a las consejerías competentes en las materias afectadas, el cual deberá ser emitido en el plazo de un mes. En el caso de que no se emita en el plazo mencionado, la administración competente para llevar a cabo la zonificación podrá adoptar las determinaciones que considere oportunas."

En Barcelona, la intervención administrativa sobre las VUT ha sido especialmente intensa. En 2017 se aprobó el Plan Especial urbanístico para la ordenación de los establecimientos de alojamiento turístico, albergues de juventud, residencias colectivas de alojamiento temporal y viviendas de uso turístico (PEUAT) ${ }^{24}$ Este plan establece en su artículo 9 que las VUT (entre otros alojamientos turísticos) solo podrán situarse en edificios en los que ninguna de sus entidades estuviera destinada al uso de vivienda en fecha de 1 de julio de 2015 y que el edificio entero deberá estar destinado a la actividad que se pretende implantar, con la única excepción de la planta baja, que se podrá destinar a otros usos admitidos siempre que no sean el de vivienda.

EI PEUAT establece el crecimiento cero de las VUT en toda la ciudad y, con el fin de evitar la saturación turística y la concentración excesiva y para garantizar un desarrollo territorial equilibrado, dispone que cuando cese la actividad de una VUT en una zona congestionada, se permitirá una nueva alta en una zona descongestionada o el reagrupamiento en la zona de mantenimiento y crecimiento.

Para la aplicación detallada de las determinaciones el PEUAT establece cuatro zonas específicas (una de ellas, subdividida a su vez en tres subzonas) que se delimitan en función de su sensibilidad para poder acoger nuevos establecimientos en atención a la intensidad de la oferta actual de alojamientos turísticos, la relación de plazas ofertadas respecto de la población residente, la saturación del espacio público y la morfología urbana - la especialización urbanística preferente del ámbito. Así, las distintas zonas en las que el PEUAT divide la ciudad se configuran de la siguiente forma:

\begin{tabular}{|l|l|l|}
\hline ZONA & OBJETIVO & $\begin{array}{l}\text { CONDICIONES DE LA IMPLANTACIÓN } \\
\text { DE ESTABLECIMIENTOS TURÍSTICOS }\end{array}$ \\
\hline ZONA 1 & $\begin{array}{l}\text { Decrecimiento } \\
\text { natural }\end{array}$ & $\begin{array}{l}\text { No se admite la implantación de nuevos } \\
\text { establecimientos ni tampoco la ampliación de } \\
\text { plazas de los establecimientos existentes. }\end{array}$ \\
\hline ZONA 2 & Mantenimiento & $\begin{array}{l}\text { La implantación de un nuevo establecimiento } \\
\text { requerirá el cumplimiento de forma conjunta } \\
\text { de una serie de condiciones de densidad. }\end{array}$ \\
\hline
\end{tabular}

\footnotetext{
${ }^{24}$ Aprobado definitivamente por el Pleno del Consell Municipal del Ayuntamiento de Barcelona, en sesión celebrada el 27 de enero de 2017.
} 


\begin{tabular}{|l|l|l|}
\hline ZONA & OBJETIVO & $\begin{array}{l}\text { CONDICIONES DE LA IMPLANTACIÓN } \\
\text { DE ESTABLECIMIENTOS TURÍSTICOS }\end{array}$ \\
\hline ZONA 3 & $\begin{array}{l}\text { Crecimiento } \\
\text { contenido }\end{array}$ & $\begin{array}{l}\text { La implantación de un nuevo establecimiento } \\
\text { requerirá el cumplimiento de forma conjunta } \\
\text { de una serie de condiciones de densidad. }\end{array}$ \\
\hline $\begin{array}{l}\text { ZONA 4 } \\
\text { (3 subzonas) }\end{array}$ & $\begin{array}{l}\text { Zonas en proceso } \\
\text { de desarrollo }\end{array}$ & $\begin{array}{l}\text { La implantación de un nuevo establecimiento } \\
\text { requerirá el cumplimiento de forma conjunta } \\
\text { de una serie de condiciones de densidad, } \\
\text { dependiendo de las subzonas de que se trate. }\end{array}$ \\
\hline
\end{tabular}

En definitiva, el PEUAT distingue cuatro zonas específicas con regulación propia, de manera que cada una de ellas tiene unas características individuales en lo referente a distribución de alojamientos, proporción entre el número de plazas que ofrecen y la población residente, relación y las condiciones en que se dan determinados usos, incidencia de las actividades en el espacio público y presencia de puntos de interés turístico.

En Madrid, el Plan Especial de regulación del uso de servicios terciarios en la clase de hospedaje de Madrid (PEH) ${ }^{25}$ contempla restricciones a la actividad de VUT en once distritos de la ciudad ${ }^{26}$, de manera que las viviendas particulares que se alquiler durante un plazo superior al de tres meses al año deben solicitar en casi todos los casos una licencia de uso terciario y, además, deben cumplir una serie de condiciones en función de la zona en la que se encuentren. Para ello, se delimitan tres zonas o anillos:

\begin{tabular}{|l|l|l|}
\hline ZONA & $\begin{array}{l}\text { CONDICIONES DE ACCESO } \\
\text { A LA VIVIENDA }\end{array}$ & $\begin{array}{l}\text { EXIGENCIA DE AUTORIZACIÓN } \\
\text { ADMINISTRATIVA }\end{array}$ \\
\hline YNILLOS 1 2 & $\begin{array}{l}\text { La VUT debe estar dotada de } \\
\text { un acceso independiente, no } \\
\text { pudiendo utilizar las puertas de } \\
\text { entrada, portales o ascensores } \\
\text { comunes al resto de viviendas. } \\
\text { El acceso no podrá ser directo } \\
\text { desde la calle a los alojamien- } \\
\text { tos, sino que deben contar con } \\
\text { una recepción o similar. }\end{array}$ & $\begin{array}{l}\text { Se exige la obtención de una } \\
\text { licencia de uso terciario. }\end{array}$ \\
\hline
\end{tabular}

${ }^{25}$ Aprobado definitivamente por el Pleno del Ayuntamiento de Madrid en sesión celebrada el 27 de marzo de 2019

${ }^{26}$ Los distritos afectados son: Centro, Arganzuela, Retiro, Salamanca, Chamartín, Tetuán, Chamberí, Moncloa-Aravaca, Latina, Carabanchel y Usera 


\begin{tabular}{|c|c|c|}
\hline ZONA & $\begin{array}{l}\text { CONDICIONES DE ACCESO A } \\
\text { LA VIVIENDA }\end{array}$ & $\begin{array}{l}\text { EXIGENCIA DE AUTORIZACIÓN } \\
\text { ADMINISTRATIVA }\end{array}$ \\
\hline ANILLO 3 & $\begin{array}{l}\text { En edificios de uso exclusivamente } \\
\text { residencial, se exigen las mismas } \\
\text { condiciones de acceso que en los } \\
\text { anillos } 1 \text { y } 2 \text {. } \\
\text { En edificios en los que ya se ad- } \\
\text { miten otras clases de uso tercia- } \\
\text { rio, como oficinas o comercios no } \\
\text { se exigen condiciones especiales } \\
\text { de acceso independiente. }\end{array}$ & $\begin{array}{l}\text { En edificios de uso exclusivamente } \\
\text { residencial se exige la obtención de } \\
\text { una licencia de uso terciario. } \\
\text { En edificios en los que ya se admi- } \\
\text { ten otras clases de uso terciario, } \\
\text { como oficinas o comercios, se ad- } \\
\text { mite el cambio de uso residencial } \\
\text { a turístico sin necesidad de autori- } \\
\text { zación turística previa. }\end{array}$ \\
\hline
\end{tabular}

En el caso de San Sebastián, la Ordenanza municipal reguladora del uso de vivienda turística y de alquiler de habitaciones en vivienda habitual para uso turístico ${ }^{27}$ justifica la intervención por la existencia de valores superiores, como son la protección del medio ambiente, el derecho al descanso de la vecindad, la necesidad de preservar el uso urbanístico residencial de vivienda en los términos establecidos en la ordenación urbanística, el interés en la dinamización económica y social del conjunto de la ciudad, con el fin de evitar procesos de gentrificación en determinadas áreas. Para ello, la norma establece la utilización de la técnica de zonificación de la ciudad en áreas en donde la implantación de las VUT recibe un uso diferenciado, dividiendo la ciudad en las siguientes zonas:

\begin{tabular}{|c|c|c|}
\hline ZONA & OBJETIVO & $\begin{array}{l}\text { CONDICIONES DE LA IMPLANTACIÓN } \\
\text { DE ESTABLECIMIENTOS TURÍSTICOS }\end{array}$ \\
\hline ZONA A & Zona saturada. & $\begin{array}{l}\text { Se prohíben totalmente implantaciones del uso urba- } \\
\text { nístico de vivienda turística, así como el alquiler de } \\
\text { habitaciones en vivienda habitual para uso turístico }\end{array}$ \\
\hline ZONA B & $\begin{array}{l}\text { Zona de alta } \\
\text { demanda. }\end{array}$ & $\begin{array}{l}\text { Se permitirá la ocupación parcial de una edificación } \\
\text { residencial para uso de vivienda turística con arreglo } \\
\text { a los siguientes criterios generales: } \\
\text { a) en la planta baja se permite el uso urbanístico de } \\
\text { VUT en las mismas condiciones de para las viviendas } \\
\text { habituales } \\
\text { b) en la primera planta alta, se permite el uso urba- } \\
\text { nístico de VUT con acceso común al de las viviendas } \\
\text { cuando su superficie útil, sumada al resto de usos } \\
\text { no residenciales en el edificio con acceso común al } \\
\text { de las viviendas sea igual o inferior a } 250 \text { m² útiles }^{2} \text { en la totalidad del edificio. } \\
\text { c) En las plantas altas se permitirá una vivienda turís- } \\
\text { tica con acceso común al de las viviendas siempre que } \\
\text { ninguna de las ubicadas por debajo esté destinada } \rightarrow\end{array}$ \\
\hline
\end{tabular}

27 Aprobada definitivamente por el Pleno del Ayuntamiento de San Sebastián en sesión celebrada el 1 de marzo de 2018 


\begin{tabular}{|c|l|l|}
\hline ZONA & OBJETIVO & $\begin{array}{l}\text { CONDICIONES DE LA IMPLANTACIÓN } \\
\text { DE ESTABLECIMIENTOS TURÍsTICOS }\end{array}$ \\
\hline ZONA B & $\begin{array}{l}\text { Zona de alta } \\
\text { demanda. }\end{array}$ & $\begin{array}{l}\text { o se proyecte destinar a uso residencial, de ma- } \\
\text { nera que todas esas plantas deben estar destinadas } \\
\text { a otro tipo de usos autorizados diversos al uso resi- } \\
\text { dencial y que su superficie útil sumada al resto de } \\
\text { usos no residenciales en el edificio, con acceso } \\
\text { común, sea igual o inferior a 250 m² útiles en la to- } \\
\text { talidad del edificio. }\end{array}$ \\
\hline ZONA C & $\begin{array}{l}\text { Zona con posibi- } \\
\text { lidad de incre- } \\
\text { mentar la oferta } \\
\text { alojativa turís- } \\
\text { tica. }\end{array}$ & $\begin{array}{l}\text { Excepcionalmente se podrán permitir sin aplicación } \\
\text { del requisito de que no exista o se proyecte uso re- } \\
\text { sidencial por debajo del solicitado de vivienda turís- } \\
\text { tica dos viviendas turísticas en plantas altas en los } \\
\text { edificios que tengan un mínimo de 7 plantas (B+6) } \\
\text { y otras dos viviendas por cada } 6 \text { plantas adicionales } \\
\text { a ubicar en cualquiera de las plantas adicionales, } \\
\text { con algunos límites de superficie. }\end{array}$ \\
\hline
\end{tabular}

Como vemos, los municipios están tomando la iniciativa en lo que se refiere al uso de técnicas de zonificación y, son excepcionales los casos en los que la regulación de la zonificación o calificación urbanística procede de normas autonómicas. ARANA GARCÍA ${ }^{28}$ advierte de que esta situación provoca que los municipios, a nivel reglamentario, tengan libertad para adoptar medidas que pueden afectar a derechos fundamentales como la propiedad o libertades fundamentales como la de empresa o la de prestación de servicios.

\section{REFLEXIONES FINALES}

La irrupción de las plataformas tecnológicas de intermediación, su auge y la evolución que han experimentado, pasando de ser plataformas colaborativas altruistas a verdaderos modelos de negocio cada vez más pujantes, han transformado el mercado de alquiler de las viviendas de uso turístico provocando una verdadera convulsión en el sector. En algunos casos, algunos sectores de la sociedad y en otros casos, los agentes económicos tradicionales han solicitado a los poderes públicos que se limiten o se restrinjan este tipo de actividades. Las Administraciones Públicas se enfrentan a un complejo reto, el de regular la actividad de forma que esta modalidad económica sea compatible con la libre competencia y con el principio de igualdad de los operadores económicos, a la vez que se permita el incremento de las opciones disponibles para los consumidores finales de alojamiento turístico, en términos de precios, localización y calidad. En el ámbito de los Ayuntamientos, las medidas más relevantes que se están tomando están relacionadas con la zonificación, determinando en qué áreas y en qué condiciones se permite el desarrollo de esta actividad, que dejará de considerarse uso residencial y pasará a ser uso terciario. Los objetivos que se persiguen, un desarrollo sostenible, la convivencia ciudadana, el acceso a una vivienda digna son, sin duda,

\footnotetext{
${ }^{28}$ E. ARANA GARCÍA, "La intervención local en las viviendas de uso turístico a través de la zonificación urbanística: requisitos y consecuencias", Revista de Estudios de la Administración Local y Autonómica, 10, 2018, pp. 22-39
} 
loables. Sin embargo, una intervención excesivamente intensa puede producir el efecto contrario, provocando un bloqueo del mercado que termine generando prácticas especulativas en el sector y atentando contra otros derechos, como el de la propiedad y la libertad de empresa, también protegidos. En definitiva, es preciso realizar una ponderación de los intereses y derechos afectados para determinar cuáles son los superiores y utilizar las técnicas de intervención administrativa, como la zonificación urbanística, con la debida cautela para alcanzar los efectos deseados.

\section{BIBLIOGRAFÍA}

E. ARANA GARCÍA, "La intervención local en las viviendas de uso turístico a través de la zonificación urbanística: requisitos y consecuencias", Revista de Estudios de la Administración Local y Autonómica, 10, 2018, pp. 22-39. https://doi.org/10.24965/reala.v0i10.10545

M.A. ARIAS MARTÍNEZ, "La integración de los inmigrantes y el acceso a la vivienda: un doble reto para la Administración española", Instituzioni del Federalismo. Revista di studi giuridici e politici, 1, 2019.

AUTORITAT CATALANA DE LA COMPETENCIA (ACCO) (2014). "Recomendaciones sobre la regulación detallada de los usos del suelo desde la óptica de la competencia. ES 8/2014". Disponible en http://acco.gencat.cat/web/.content/80 acco/documents/arxius/actuacions/ES 82014 USOS DEL SOL E SP.pdf (Último acceso: 28 de julio de 2019)

C. CABRERIZO, J. SEQUERA, P. BACHILLER, "Entre la turistificación y los espacios de resistencia en el centro de Madrid. Algunas claves para (re)pensar la ciudad turística", Ecología Política, 52, 2016, pp. 78-82.

COMISIÓN NACIONAL DE LOS MERCADOS Y LA COMPETENCIA (CNMC) (2018). "Estudio sobre la regulación de las viviendas de uso turístico en España. E/CNMC/003/18" disponible en https://www.cnmc.es/sites/default/files/2133063 2.pdf (Último acceso: 28 de julio de 2019)

Comisión Nacional de los Mercados y la Competencia (CNMC), Resultados preliminares del estudio de los nuevos modelos de prestación de servicios y la economía colaborativa, 2016. Disponible en https://docs.google.com/document/d/1n65MjUaTmRLuZCqTIlayWvobVqreR-iAzsz1mhxy2y0/edit?pref=2\&pli=1\# (Último acceso: 28 de julio de 2019)

E. DESDENTADO DAROCA, "Aspectos jurídico-administrativos de las viviendas de uso turístico" en VV.AA. (M. Lucas Durán, dir.) Las viviendas de uso turístico y su regulación jurídica. Un enfoque multidisciplinar, Thomson Reuters Aranzadi, Navarra, 2019, pp. 41 - 93.

J. FRANCH FLUXÁ, "Las comunidades autónomas ante el alojamiento colaborativo", en VV.AA. (S. Rodríguez Marín y A. Muñoz García, coords.), Aspectos legales de la economía colaborativa y bajo demanda en plataformas digitales, Wolters Kluwer, Madrid, 2018, pp.221-243

J. GIL, "¿Cómo regular el hospedaje entre particulares? Criterios de regulación utilizando el caso de «Airbnb»" en VV.AA. (A. M. de la Encarnación, dir.) La regulación del alojamiento colaborativo. Viviendas de uso turístico y alquiler de corta estancia en el Derecho español, Thomson Reuters Aranzadi, Navarra, 2018, pp. 121-147. 
R. GLASS, London aspects of change, MacGibbon \& Kee, Londres, 1965.

K. GOTHAM, "Tourism Gentrification: the case of New Orleans 'Vieux Carré (French Quarter)", Urban Studies, vol. 42, no 7, 2005, pp. 1009-1121. https://doi.org/10.1080/00420980500120881

N.A. GUILLÉN NAVARRO, "Viviendas de uso turístico y turismofobia" en V.AA. (A. M. de la Encarnación, dir.) La regulación del alojamiento colaborativo. Viviendas de uso turístico y alquiler de corta estancia en el Derecho español, Thomson Reuters Aranzadi, Navarra, 2018, pp. 171-186.

M. LORA-TAMAYO VALLVÉ, "Economía colaborativa y alojamiento" en VV.AA. (J.J. Montero Pascual, dir. ), La regulación de la economía colaborativa, Tirant lo Blanch, Valencia, 2017

A. NOGUEIRA LÓPEZ, "Las competencias sobre el alojamiento «colaborativo». Entre el «derecho a la ciudad», la garantía de la vivienda y la dura lex económica" en VV.AA. (A. M. de la Encarnación, dir.) La regulación del alojamiento colaborativo. Viviendas de uso turístico y alquiler de corta estancia en el Derecho español, Thomson Reuters Aranzadi, Navarra, 2018, pp. 231-259

A. ROMÁN MÁRQUEZ, "Planificación urbanística del turismo: la regulación de las viviendas de uso turístico en Madrid y Barcelona", Revista de Estudios de la Administración Local y Autonómica, 10, 2018, pp. 22-39. https://doi.org/10.24965/reala.v0i10.10566

J.M. SOCÍAS CAMACHO, "Estado regulador y alojamiento «colaborativo» en V.AA. (A. M. de la Encarnación, dir.) La regulación del alojamiento colaborativo. Viviendas de uso turístico y alquiler de corta estancia en el Derecho español, Thomson Reuters Aranzadi, Navarra, 2018, pp. 95-119

N. STORS, A. KAGERMEIER "The sharing economy and its role in metropolitan tourism" en VV.AA. (M. Gravari-Barbas, S. Guinand, ed.) Tourism gentrification in contemporary metropolises, Routledge, Nueva York, 2017, pp. 181-205. https://doi.org/10.4324/9781315629759-8

M. TURNER, "Global head of civic partnerships at Airbnb", A. Boswijk Interviewer, 2013, en J. OSKAM, A. Boswijk, "Airbnb: the future of networked hospitality businesses," Journal of Tourism Futures, Vol. 2, 2016, pp. $22-42$. https://doi.org/10.1108/JTF-11-2015-0048

M. VAQUER CABALLERÍA, "La consolidación del principio de desarrollo territorial y urbano sostenible en la última década", Revista de Derecho Urbanístico y Medio Ambiente, 311, 2017, pp. 499-525. 